\section{Representative \\ Democracy and \\ the Profession}

Neville Holmes, University of Tasmania
(Australian Financial Review, 29 Oct. 2001, p. 56).

The tenor of these campaign tactics indicates that the Australian government-and by extension the governments of similar countries-is more concerned with the economy than with its citizenry, regardless of how that citizenry voted.

The new Federal Minister for Education's post-election proclamation underlined this theme. The minister accused the university sector of being reluctant to embrace change, then promised to "consult with business over what changes are necessary

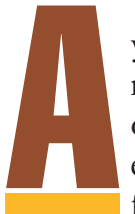

year ago, I considered the now all but forgotten fiasco of the 2000 US Presidential election ("US Electoral Reform: The Obvious Obligation," Computer, Feb. 2001, pp. 128, 126-127) and suggested ways that digital technology might help make elections to an office such as the presidency more democratic. The election of democratic representatives, on the other hand, presents a far more complex issue that offers more significant possibilities for exploiting digital technology.

\section{OCHLOCRACY AND ECONOMOCRACY}

Democracy means rule by the people, and the term refers in an abstract way to a process or institution under which government openly solicits, preserves, and fosters information about its citizens' interests. At the heart of a typical democratic government lies a chamber of representatives that decides issues by vote.

We must not confuse democracy with ochlocracy-or mob rule-the nightmare outcome likely to occur if those who advocate using the marvels of digital technology to give everyone voting rights on every issue have their way. Anyone who doubts the hideous dangers of this approach should read Naomi Klein's description in No Logo (Flamingo Press, London, 2000; see also http://nologo.org/publication.

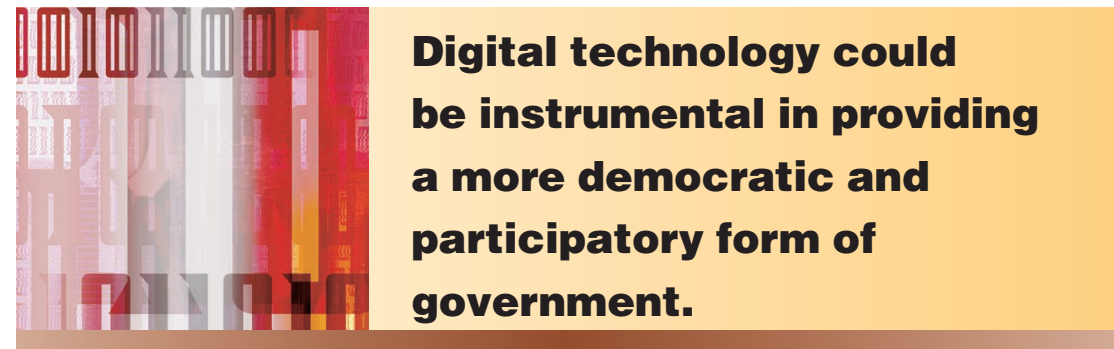

shtml) of how effectively branding can influence public attitudes. In an online ochlocracy, branding would be a superb technique for enabling special interest groups to become mobsters.

Economocracy lies near the end of the political spectrum opposite ochlocracy, and is alleged by many to be the creed of Australia's two largest political parties, which contested the federal elections this past November. The main opposition party, the Australian Labor Party, promised that if elected it would implement an elaborately planned "Knowledge Economy."

Meanwhile, the incumbent Liberal Party based its campaign on claims of superior economic management. The Liberals had ousted the Labor Party from office in 1996 by condemning its economic management, citing increased foreign debt as "the final indictment."

Yet under Liberal Party rule, Australia's foreign debt rose from 38.2 percent of gross domestic product in June 1996 to 46.7 percent in June 2001 to ensure the universities better meet the community's needs" (Australian Financial Review, 17 Dec. 2001, p.3).

Whether justified or not, the perception of incipient economocracy must be reversed. For, to paraphrase a much admired judicial maxim, democracy must not only be done, it must also be seen to be done.

Making elected representatives more democratic and responsive to those represented, or at least less liable to accusations of moving in the opposite direction, seems an obvious measure. The computing profession has a responsibility to take part in publicly discussing democratic reform, and in particular to make suggestions about how such reform could employ digital technology.

The need for reform extends beyond Australia, given that many of the Organization for Economic Cooperation and Development's 29 other members appear just as economocratically

Continued on page 118 
inclined. The organization's very name suggests that tendency.

\section{ONE CITIZEN, ONE VOTE}

Democracy in its purest form demands that each citizen be able to exert the same influence as do all others. Following this principle, every voter's ballot counts as exactly one vote in democratic elections.

In present-day chambers of representatives, however, it's not the voters who count equally, but the representatives. A representative's vote thus carries the same weight whether he represents 100,000 citizens or $1,000,000$. Three clearly undemocratic consequences arise from this system.

First, there is a restraint on allowing a sparse rural electorate to have fewer citizens than a compact urban electorate. Imbalance in electorate populations has been accepted in many countries to counter the city dwellers' advantage of easier access to their representative, but this practice soon leads to an abuse called malapportionment (http://www. utahhistorytogo.org/lemalapport.shtml). Governments usually counter malapportionment with equal-population electorates, but in Australia federal electoral areas range from 26 square kilometers to far more than 2 million square kilometers. Maintaining the democratically necessary personal presence in these larger areas presents representatives with a staggering challenge.

Second, equalizing the number of citizens within established electoral boundaries makes it difficult to have such boundaries match the community's natural borders. This approach undemocratically fractures some electorates' communities, leading to poor coordination and disparities between electorates. These artificial boundaries also mix parts of different natural communities within electorates, leading to conflicts of interest and difficulties in providing clear and forceful representation of community interests.

Third, when the population in a region fluctuates, redrawing electoral boundaries to keep the electorates equal in population can confound representatives with a continually shifting constituency, making it hard for them to press effectively for recognition of their constituent's interests.

Digital technology can enable reforms that would greatly lessen these difficulties. It could, for example, support the principle of "one voter, one vote." With fairly simple identification and voting equipment installed in its debating chamber, a legislative body

\section{Digital technology could support the sharing of a state's voting power between representatives in proportion to the votes they are elected by.}

could give every elected representative one vote for every voter in their electorate.

Each representative would thus cast a different number of votes, and although rules would be needed to prevent a gross imbalance between electorates, mild imbalance could be quite acceptable in improving quality of representation. Australia currently aims to achieve a limit of 3.5 percent imbalance, a very low figure that leads to electoral boundaries that writhe like screen savers.

Allowing mild imbalances, say up to one third, would also eliminate the need to continually redraw electoral boundaries. Better still, on those rare occasions when gross imbalance develops, redrawing the boundaries would be much simpler because the allowed mild imbalance would permit more natural electorate coalescing and splitting.

A digital voting system would offer an additional advantage to electoral systems that do not make registration and voting compulsory: Representatives would need to be responsive to their voters if they wanted to increase voter turnout and, in turn, their own influence. Likewise, ignoring voters would likely cause a representative's influence to dwindle.

\section{THE TWO-PARTY VOTE}

A digital voting system could also eliminate the classical gerrymander. This maneuver, often made possible by weak or corrupt electoral administrations, aims to draw electoral boundaries so that the ruling party wins its electorates by a small margin, but crowds the opposition party's voters together into fewer but more populous districts. This tactic makes it possible for a party to have a majority of representatives elected with much less than a majority of votes overall.

To quash gerrymandering, an electoral administration could create much larger electorates, each of which would have two representatives from different political parties. When voting as representatives, each would cast as many votes as they received in the election.

For example, if an electorate's representative A took office with 256,000 votes, and representative $B$ with 199,000, then A would cast 256,000 votes on any issue, while $B$ could cast only 199,000. Digital technology would make administering such a system easy.

Simple variations on this scheme could make direct representation of minor-party voters possible, even across multiple electorates. In federal governments that have a chamber, such as the US Senate, in which states of the federation have equal representation, digital technology could support the sharing of any state's voting power between representatives in proportion to the votes they are elected by. This approach would be simpler and fairer than the proportional representation schemes now adopted in some countries (http://www.prairienet.org/icpr/ links.html).

Having two representatives for an electorate provides the significant additional advantage of helping voters avoid the feelings of despair and apathy that often occur under typical, sin- 
gle-winner election systems. When their preferred candidate loses, or when a candidate they strongly object to wins, voters in such systems feel unrepresented, diminishing their faith in the democratic process.

\section{CONTINUOUS ELECTIONS}

The voting schemes I've suggested leave intact one great perceived failing of present systems: the great brouhaha surrounding the periodic general election of representatives.

In the time leading up to an election, candidates barrage the populace with bombast, promises, and ads, while marginal but key electorates often receive lavish bribes-usually in the form of lucrative government contracts-in exchange for votes. Many voters feel that their representatives only really care about them at election time. At other times, those representatives pay more attention to the interests of those who supported their election campaigns financially in the past or might do so in the future.

We could employ digital technology to implement continuous elections, thereby reducing this problem greatly. This radical and apparently impractical solution has advantages so profound we should not dismiss it out of hand. Continuous elections would require a computer-based electoral system and an administration under which citizens could enter an electoral office, either physically or electronically, and cast a vote at any time, with certain restrictions.

The electoral administration would set the voting entitlement of representatives for any sitting of a legislative chamber at some statutory time shortly before the sitting. Electoral voting figures would be published regularlysay weekly—so that representatives would get frequent and direct feedback on how the electorate viewed their performance. This system would also eliminate the posturing and rhetoric that comes with opinion polling.

Avoiding instability is a system engineering principle usually applied by smoothing inputs. In a continuous election, system inputs could be smoothed by forbidding change of any vote within six months of it being cast. Another smoothing technique would call for old votes to lapse after a strict three years unless recast.

We could eliminate another source of instability by providing an orderly transition from a retiring representative to a new one, allowing them to split their party's vote for a transition

\section{Governments need our support to ensure that reformers make the best possible use of digital machinery.}

period. The continuous election system could even allow the electorate to choose between candidates for replacement.

Instability could still occur if we apply continuous elections to a parliamentary system in which governments form from the elected representatives of the majority party or from the majority coalition of parties. But rapid changes in such governments could be prevented by applying a honeymoon bias for the voting entitlements of a new government's members, a bias that would gradually diminish to zero, or even beyond. For example, digital technology could apply a 10 percent honeymoon bias upon change of government, making each normal vote worth 1.1, and diminish that bias for each subsequent legislative sitting at a rate that would bring the bias to zero after eighteen months. If occasional changes of government were thought worth encouraging, the bias could continue to be diminished until it reached -5 percent.

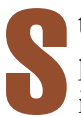
table governments consist of politicians who see their own interests tightly bound up in the political system's stability. Thus, keep- ing the system unchanged provides the only issue short of a national emergency likely to attract overt and enthusiastic cross-party support.

To achieve any democratic reform in stable countries, the electorate must first be clearly aware of the nature and benefits of potential practical reforms, then must press strongly for such reforms. The necessary reforms can be envisioned clearly only after careful and detailed consideration of reform measures, a process in which computing professionals can play an important role. As technologists, governments need our support to ensure that reformers make the best possible use of digital machinery, and to ensure that the public clearly understands any such use. As system engineers, governments need our support to ensure that any reforms proposed are, as a system, practical and reliable, and to anticipate and counter the inevitable politically motivated criticisms. This last task presents an especially daunting challenge because of the many loopholes and pitfalls that must be avoided.

Countries with unstable governments face a much more complex situation. Divisiveness, chaos, and uncertainty present at best a moving target for reform, and they may make implementing digital technology irrelevant.

Any computing professional who feels doubt about the directions a government is taking has a duty to air those doubts, as I have done here. If that professional sees a need for democratic reform that would benefit the community, duty also demands that the professional advise the community about how to best use digital technology and system engineering in pursuit of that reform.

Neville Holmes is an honorary research associate and a lecturer under contract at the University of Tasmania's School of Computing. Contact himatneville.holmes@utas.edu.au. 